\title{
O COMPORTAMENTO INFORMACIONAL DE LÍDERES RELIGIOSOS EM BELO HORIZONTE
}

\section{THE INFORMATION BEHAVIOR OF RELIGIOUS LEADERS IN BELO HORIZONTE}

${ }^{1}$ Doutoranda em Ciência da Informação pela

Universidade Federal de Minas Gerais (UFMG).

E-mail: gilmaramachadoju@hotmail.com

2 Professor do Programa de Pós-Graduação em Ciência da Informação da Universidade Federal de Minas Gerais (UFMG).

\section{E-mail: ricardobarbosa@eci.ufmg.br}

\section{ACESSO ABERTO}

Copyright: Esta obra está licenciada com uma Licença Creative Commons Atribuição 4.0 Internacional. $(\mathrm{cc}) \mathrm{EY}$

Conflito de interesses: Os autores declaram que não há conflito de interesses.

\section{Financiamento: Não há.}

Declaração de Disponibilidade dos dados: Todos os dados relevantes estão disponíveis neste artigo.

Recebido em: 24/10/2018.

Aceito em: 17/12/2018.

Revisado em: 22/12/2018.

\section{Como citar este artigo:}

MACHADO, Gilmara de Cássia; BARBOSA, Ricardo Rodrigues. 0 comportamento informacional de líderes religiosos em Belo Horizonte. Informação em Pauta, Fortaleza, v. 3, n. 2, p. 10-30, jul./dez. 2018. DOI: https://doi.org/10.32810/25253468.ip.v3i2.2018.36583.10-30.

\section{RESUMO}

A informação é a base da dinâmica dos processos produtivos e organizacionais e seu uso está vinculado à capacidade de interpretação,

\author{
Gilmara de Cássia Machado ${ }^{1}$ \\ Ricardo Rodrigues Barbosa ${ }^{2}$
}

compreensão, inovação e gestão visando à tomada de decisão. Considerando o valor da informação esta pesquisa teve como objetivo analisar como ocorre o processo de busca e uso da informação por líderes religiosos para embasar o processo de tomada de decisão em seu dia a dia. A metodologia adotada foi a pesquisa qualitativa, descritiva com base em estudo de caso em que a coleta de dados se deu por meio de entrevista. A partir dos dados coletados foi possível perceber que as necessidades informacionais dos líderes religiosos estão pautadas, sobretudo por questões religiosas que visam auxiliar no exercício do sacerdócio. Além do mais, os líderes religiosos estão preocupados com o sentido da informação, condições, padrões e regras de uso visando orientar espiritualmente bem como trazer informações diversas que visam o conhecimento e aprendizado dos fiéis. Já as decisões visam atender as diretrizes da organização por meio de regras formais o que leva a um comportamento regulado por normas e rotinas, de forma que a organização possa atuar de uma maneira procedimental e intencional.

Palavras-chave: Líderes Religiosos. Informação. Necessidade, busca e uso da Informação. Tomada de Decisão.

\section{ABSTRACT}

Information is the basis of the dynamics of productive and organizational processes and its use is linked to the capacity for interpretation, understanding, innovation and management for decision making. Considering the value of the information, this research had as objective to analyze how the process of search and use of information by religious leaders to support the process of decision making in their day to day occurs. The methodology adopted was the qualitative, descriptive research based on a case study in which the data collection was done through an interview. From the collected data it was possible to perceive that the informational needs of the religious leaders are based, mainly by religious questions that aim to 
assist in the exercise of the priesthood. Moreover, religious leaders are concerned with the sense of information, conditions, standards and rules of use aimed at spiritually orienting as well as bringing diverse information that aim at the knowledge and learning of the faithful. The decisions are aimed at meeting the organization's guidelines through formal rules, which leads to behavior regulated by norms and routines, so that the organization can act in a procedural and intentional way.

Keywords: Religious Leaders. Information. Need, search and use of information. Decision Making.

\section{INTRODUÇÃO}

A informação é uma ferramenta indispensável para as organizações visto que ela assume posição de destaque devido à sua ação transformadora no sentido de oportunizar o desempenho organizacional e auxiliar os gestores na tomada de decisão e na elaboração de ações estratégicas, táticas e operacionais. Segundo Barbosa (2008, p. 2):

[...] à medida que os ambientes profissionais e de negócios se tornam mais complexos e mutantes, a informação se transforma, indiscutivelmente, em uma arma capaz de garantir a devida antecipação e análise de tendências, bem como a capacidade de adaptação, de aprendizagem e de inovação.

A informação é o alicerce da dinâmica dos processos produtivos e organizacionais, sendo ao mesmo tempo derivado destes. Seu uso está relacionado à capacidade de interpretação, compreensão, inovação e gerenciamento visando à tomada de decisão.

Com base nisso podemos destacar a religião, esta tem sido reconhecida pela sua importância social na influência do comportamento humano. Para Vitell (2005), a religião exerce determinadas atitudes e crenças, além de influenciar crenças e o comportamento do indivíduo em diversas situações. Observa-se também um grande movimento em torno da religião e da religiosidade, sobretudo porque esta é guiada pela discussão de atribuição de sentido, de valores e de propósito pessoal da vida (BERGER, 1985).

Embora sejam tradicionalmente conhecidos por seus aspectos sagrados, em contraste com as empresas e/ou organizações, que visam ao lucro financeiro, os sistemas religiosos vêm se modificando a fim de competir com outros sistemas de significação existencial (BERGER, 1985).

Para Silva (2007), a estrutura organizacional das igrejas admite certa liberdade de atuação, o que colabora para o exercício da criatividade, da intuição e da autonomia. Ademais, o forte sentido que o trabalho assume para seus líderes - principalmente no 
que tange à questão vocacional do trabalho, vinculando os valores pessoais aos organizacionais, a possibilidade de se sentir útil e elemento da organização e também de servir à comunidade - permite uma forte transcendência da questão comercial e/ou profissional. Silva (2007) aponta ainda que o prazer percebido no trabalho dos líderes religiosos está ligado a dois aspectos importantes: gerenciamento e o significado dessa atividade.

Além disso, há que se destacar que para que o sistema religioso funcione é necessário que seus líderes se atentem para além da gestão, ou seja, é de fundamental importância que o líder religioso pense também na gestão da informação e do conhecimento que este administra para si, para sua instituição e para seus seguidores.

Tendo em vista o valor da informação e com base no exposto, esta pesquisa teve como objetivo analisar como ocorre o processo de busca e uso da informação pelos líderes religiosos para embasar o processo de tomada de decisão em seu dia a dia.

Cabe ressaltar que para melhorar o desempenho organizacional, o conhecimento é o principal recurso estratégico que, se gerido adequadamente, permite a criação de valor à organização, promovendo a aprendizagem organizacional, a competitividade e a inovação.

\section{A GESTÃO DA INFORMAÇÃO E DO CONHECIMENTO NAS ORGANIZAÇÕES}

Informação é um conceito complexo uma vez que possui múltiplos sentidos nos diversos campos do conhecimento. Em algumas linhas de pesquisa da Ciência da Informação esse fenômeno é entendido como algo concreto, sendo conferido a este a objetividade, que pode ser sinônimo do conhecimento, o que o torna passível de ser mensurado; ou, em outras linhas de pesquisa, a informação pode ser vista como algo simbólico, concebida a partir da interação cotidiana dos indivíduos em seu contexto de ação. Para Le Coadic (2004, p. 4):

[...] a informação é um conhecimento inscrito (registrado) em forma escrita (impressa ou digital), oral ou audiovisual, em um suporte. A informação comporta um elemento de sentido. É um significado transmitido a um ser consciente por meio de uma mensagem inscrita em um suporte espacialtemporal. 
Esta concepção independe do usuário, ainda que se encontre inscrita em uma conduta social de comunicação, pois os contextos, os conhecimentos, as vivências dos indivíduos têm pouca influência no processo de recepção e no sentido da informação.

Já Pacheco (1995, p.21) trabalha com a concepção da informação enquanto artefato. Para a autora, artefato pode ser entendido como "qualquer objeto confeccionado pelo homem".

Se a informação é um artefato ela foi criada num tempo, espaço e forma específicos, que formam um dos contextos pelo qual deve ser interpretada, o contexto de sua geração. Sendo artefato ela pode ser utilizada num contexto distinto daquele para o qual e no qual foi produzida, sendo, portanto, passível de recontextualização (PACHECO, 1995, p. 21).

Pacheco (1995) afirma que existem no artefato informação pelo menos dois significados: a produção e a recepção. 0 significado atribuído pelo usuário independe da vontade e do significado atribuído pelo produtor, ainda que este possa influenciar aquele. Ainda assim, o significado do artefato informação pode ir além das barreiras espaciais e temporais que separam seus contextos de produção e uso.

Para Cardoso (1996), o termo informação está carregado de ambiguidade, confundindo-se com comunicação, dado, instrução e conhecimento. Para a autora, a informação possui duas dimensões associadas: a pessoal e a coletiva.

A dimensão pessoal da informação manifesta-se pelo acervo de soluções e interpretações que acumulamos no desenrolar de nossa biografia, através daquilo que experenciamos e que nos fornece pistas para lidarmos com novas experiências. A dimensão coletiva identifica-se com fragmentos do conhecimento produzido desde que o mundo é mundo, ou seja, as sistematizações e interpretações de experiências disponibilizadas socialmente, ainda que não se possa deixar de destacar que tal disponibilização ocorre diversamente entre os indivíduos em função dos diferentes lugares que ocupam na estrutura social (CARDOSO, 1996, p. 72).

Ainda que exista uma diversidade de significados sobre o termo informação, busca-se aqui uma abordagem que destaque o contexto da produção, mediação e recepção, e o papel dos usuários, ou receptores, na construção do sentido da informação.

Assim, de acordo com Marteleto (1995), a informação estará sempre atrelada a uma possibilidade de sentido e se refere à relação dos indivíduos com a realidade, bem como aos artefatos elaborados pelas relações e práticas sociais, formando relações estreitas com o conceito de cultura. Marteleto (1995) afirma ainda que a informação é tudo que circunda o indivíduo e faz sentido para ele. Ela não é apenas um significado disseminado, uma vez que quem define seu sentido são os indivíduos inseridos em um 
contexto, e o conhecimento é construído nas interações cotidianas dos indivíduos entre si e com os objetos do seu mundo. Este conhecimento é a convergência de diversos tipos de conhecimento, como o conhecimento tácito, que é o conhecimento internalizado do indivíduo; o conhecimento científico, que é o conhecimento referente às práticas científicas e o conhecimento prático, que diz respeito à execução de uma ação; dentre outros.

Deste modo, as práticas informacionais de um grupo são fruto de suas demandas concretas e carregam consigo forte componente ideológico, o que para Lopes e Valentim (2008) tanto a relevância quanto a importância de uma dada informação, são qualidades dadas pelo usuário da informação, visto que é este usuário que busca se informar a partir de incertezas, curiosidade, lacuna ou necessidade. Em razão disso, as autoras afirmam que um trabalho informacional é realizado à luz da mediação, pois medeia o contexto da necessidade do usuário com as informações existentes. Destacam ainda que a informação está situada no segmento não estruturado, ou seja, quem trabalhar essa informação antes dela ser comunicada, deverá desenvolver as atividades informacionais a fim de disseminá-las da melhor forma ao seu público alvo, promovendo a mediação antes mesmo que o usuário tenha uma determinada necessidade informacional.

Para Choo (2002, p.21), “a busca da informação é o processo pelo qual o indivíduo procura obter informações com um propósito definido, de modo a mudar seu nível de conhecimento", ou seja, a informação é o meio para extrair e construir o conhecimento. "A informação é um fluxo de mensagens, enquanto o conhecimento é criado pelo mesmo fluxo de informação, ancorado nas crenças e no compromisso de seu portador" (NONAKA; TAKEUCHI, 2008, p.56). Para estes autores, "tanto a informação quanto o conhecimento são específicos ao contexto e relacionais por dependerem da situação, sendo criados dinamicamente na interação social entre as pessoas" (NONAKA, TAKEUCHI, 2008, p.57). Já "a inteligência pode ser vista como o conhecimento que foi sintetizado e aplicado à determinada situação". “[...] é uma habilidade puramente humana baseada em experiência e intuição. [...] e a experiência é uma agregação de valor ao processo decisório de uma organização" (MORESI, 2001, p.119-120).

Com base no exposto, a informação, entendida como um bem pode e deve ser gerenciada, uma vez que esta se torna a base da administração dos recursos de informação, que "consiste na visão integrada de todos os recursos envolvidos no ciclo de 
informação, incluindo a informação propriamente dita (conteúdo), os recursos tecnológicos e também os recursos humanos" (TARAPANOFF, 2001, p. 44).

Já o conhecimento, segundo Nonaka e Takeuchi (1997) pode ser entendido como um processo contínuo para as organizações:

[...] criação do conhecimento é um processo contínuo, direcionado pela intenção organizacional, que é definida como uma aspiração, de uma organização, às suas metas. A sua vantagem é a criação de um 'ambiente de conhecimento', voltado para o compartilhamento, que gera mais competitividade e melhores decisões (NONAKA; TAKEUCHI, 1997).

Para Barbosa (2008), a informação e o conhecimento são fenômenos indissociáveis e complementares da vida organizacional. A informação se transforma em uma arma capaz de garantir a devida antecipação e análise de tendências, bem como a capacidade de argumentação, de aprendizagem e de inovação.

\begin{abstract}
Administrar ou gerenciar o conhecimento não implica exercer controle direto sobre o conhecimento pessoal. Significa sim, o planejamento e controle do contexto, enfim, das situações nas quais esse conhecimento possa ser produzido, registrado, organizado, compartilhado, disseminado e utilizado de forma a possibilitar melhores decisões, melhor acompanhamento de eventos e tendências externas e uma contínua adaptação da empresa a condições sempre mutáveis e desafiadoras do ambiente onde atua (BARBOSA, 2008, p. 11).
\end{abstract}

Logo, o conhecimento, uma vez registrado, se transforma em informação e esta, uma vez internalizada, se torna conhecimento. Dessa forma, "o principal objetivo da gestão da informação é identificar e potencializar os recursos informacionais de uma organização e sua capacidade de informação, ensiná-la a aprender e adaptar-se às mudanças ambientais" (TARAPANOFF, 2001, p. 44).

A gestão do conhecimento se efetua num imbricado contexto de cultura e práticas organizacionais. Tendo em vista que a cultura organizacional diz respeito ao conjunto de pressupostos e valores compartilhados pelas pessoas da organização (BARBOSA, 2008), as práticas organizacionais são estabelecidas, por sua vez, pelo conjunto de atividades e serviços desenvolvidos pelas pessoas que constituem uma organização.

Barbosa (2008) esclarece que uma organização do conhecimento diz respeito àquela em que o conjunto de saberes individuais e coletivos compartilhados pelo grupo é tratado como um ativo valioso, que permite a compreensão e superação de contingências ambientais. Para este autor, um ambiente organizacional propício à gestão da informação e do conhecimento se apresenta como aquele em que os sujeitos que compõem a organização se constituem em verdadeiros construtores, compartilhadores e 
consumidores de informação e conhecimento. Portanto, é necessário compreender o conhecimento como principal ativo das organizações, visto que este se apresenta como o principal elemento na competitividade sustentável.

\section{O COMPORTAMENTO INFORMACIONAL}

Todo comportamento implica em uma escolha, seja consciente ou inconsciente. Esta escolha é continuamente motivada pelas alternativas que se tem, pelas restrições que o tempo estabelece ao processo, pelo domínio da situação ou pelo conhecimento que se tem do cenário onde se desenrola o comportamento, pelas expectativas de sucesso das escolhas alcançadas e pelas características do grupo envolvido na situação que gerou o comportamento em questão, caso exista (SIMON, 1979).

Nesta perspectiva, o comportamento informacional abarca todo comportamento humano referente à identificação de necessidades informacionais e sobre a forma como se exploram essas informações apontadas como necessárias. Abrange também, a busca por elas, seja de forma ativa ou passiva, por qualquer fonte ou canal de informação, além da sua utilização. Neste comportamento, não se pode deixar levar em consideração os fatores que podem dificultar ou impulsionar estes processos (WILSON, 1999; WILSON, 2000).

Para Ginman (1988, p. 93), a cultura da informação pode ser vista como a cultura em que "a transformação dos recursos intelectuais é mantida ao lado da transformação dos recursos materiais". Os recursos preliminares para este tipo de transformação são oriundos dos diferentes tipos de conhecimento e informação. 0 resultado alcançado é um produto intelectual processado que é necessário para que as atividades materiais funcionem e se desenvolvam de forma positiva, ou seja, a cultura da informação é um objetivo estratégico e deve ser planejada tanto quanto a transformação dos recursos físicos.

Choo (2003) analisa a cultura da informação como os padrões socialmente compartilhados de comportamentos, normas e valores que definem o significado e o uso da informação em uma organização. Os valores são as crenças fundamentadas sobre o papel e a contribuição da informação para a organização. As normas são regras ou padrões aceitos e que definem quais comportamentos são esperados na organização. As 
práticas são padrões de comportamento repetidos que envolvem funções organizacionais, estruturas e formas de interação.

Cabe destacar que as organizações desenvolvem sua própria cultura de busca e uso de informações, estabelecendo valores e normas. Assim, para entender o comportamento da informação nas organizações é necessário entender como as organizações são simultaneamente sistemas de busca de informação e de criação de crenças, onde a informação é moldada pelas práticas epistêmicas, tanto quanto as crenças que são os resultados da busca e do uso da informação. Além do mais, a informação está condicionada às dimensões situacionais próprias, gerada de maneira dinâmica e harmônica na interação entre o meio e o sujeito, uma vez que "a busca da informação é o processo pelo qual o indivíduo procura obter informações com um propósito definido, de modo a mudar o seu nível de conhecimento" (CHOO, 2003, p. 21).

"Conceitualmente, a busca da informação ocorre em três estágios: o reconhecimento das necessidades de informação, que leva à busca e depois ao uso da informação" (CHOO, 2003, p. 96). Segundo Barbosa (1997), o comportamento humano relacionado à busca de informação nas organizações é um processo complexo e necessita de vários fatores individuais ou coletivos, como estilo cognitivo, área de atuação, nível hierárquico, existência de procedimentos padronizados para lidar com a informação, custos dentre outros. Para o autor, um dos aspectos mais importantes desse fenômeno é o uso de fontes de informação.

Por comportamento informacional podemos entender que se trata de todo comportamento humano relacionado às fontes e canais de informação, incluindo a busca ativa e passiva de informação e o uso da informação. Isso inclui a comunicação pessoal e presencial, assim como a recepção passiva de informação, como a que é transmitida ao público quando este assiste aos comerciais da televisão sem qualquer intenção específica em relação à informação fornecida (WILSON, 2000, p. 49).

Destaca-se que o comportamento é algo próprio dos indivíduos ao longo de sua vida. Para a sua compreensão, é essencial compreender o espaço e o tempo do acesso, o uso e o compartilhamento da informação, além do mais os processos cognitivos são cruciais para se buscar a informação necessária.

A competência em informação está associada ao comportamento informacional, tendo em vista que considera as atitudes do sujeito como parte de seu conceito. A competência considera as capacidades e experiências dos indivíduos como elementos impactantes em sua percepção. Desta forma, a competência em informação completa os 
estudos voltados para o comportamento informacional (OTTONICAR; NASCIMENTO; BASSETTO, 2018).

Já as necessidades informacionais, segundo Silveira e Oddone (2007) advêm de situações referentes às atividades profissionais de cada indivíduo. Influenciadas, sobretudo por fatores pessoais, neste caso as necessidades informacionais apresentam características mais gerais quando analisadas por grupos de usuários, uma vez que as particularidades e o contexto de cada grupo podem motivar certo padrão.

Para Choo (2003, p. 99), “as necessidades de informação são muitas vezes entendidas como as necessidades cognitivas de uma pessoa: falhas ou deficiências de conhecimento ou compreensão que podem ser expressas em perguntas ou tópicos colocados perante um sistema ou fonte de informação". "A necessidade informacional seria então a condição na qual certa informação contribui para atender a um propósito de informação genuíno ou legítimo" (SILVEIRA; ODDONE, 2007, p. 119).

Segundo Choo (2003, p. 99), “a busca da informação é o processo humano e social por meio do qual a informação se torna útil para um indivíduo ou grupo". Já "o resultado do uso da informação é uma mudança no estado de conhecimento do indivíduo ou de sua capacidade de agir" (CHOO, 2003, p. 99). Para ele "envolve a seleção e o processamento da informação, de modo a responder a uma pergunta, resolver um problema, tomar uma decisão, negociar uma posição ou entender uma situação" (CHOO, 2003, p. 99).

As necessidades informacionais exprimem um estado de conhecimento no qual alguém se depara quando se relaciona com a imposição de uma informação que lhe falta e lhe é necessária para continuar um trabalho. Ela surge de um impulso de ordem cognitiva, seguido pela existência de um dado contexto e pela percepção de um estado de conhecimento insuficiente ou inadequado. Ela é evolutiva e extensiva tendo em vista que esta muda com o tempo sob o efeito da exposição às diferentes informações iniciais e é produzida dinamicamente motivando novas necessidades. A necessidade informacional não pode estar separada do contexto, da situação, do ambiente, que são essenciais para estabelecer o seu diagnóstico (LE COADIC, 2004). 


\section{O PROCESSO DE TOMADA DE DECISÃO}

A tomada de decisões é intrínseca ao ser humano e ocorre nas mais diversas circunstâncias, idades e posições sociais. Em uma organização as decisões são frequentemente tomadas e é este processo que continuamente reorienta seus objetivos. Para Choo (2003, p. 247),

[...] a tomada de decisão formal nas organizações é estruturada por procedimentos e regras que especificam papeis, métodos e normas. A ideia é que as regras e rotinas esclareçam o necessário processamento de informação diante de problemas complexos, incorporem técnicas eficientes e confiáveis aprendidas com a experiência e coordenem ações e resultados dos diferentes grupos organizacionais.

Acrescenta ainda que:

[...] seguir rotinas e procedimentos pode institucionalizar certas visões de mundo, formar hábitos de aquisição e transmissão de informações, e estabelecer valores e normas capazes de influenciar a maneira como a organização lida com a escolha e a incerteza. 0 resultado que se espera dessa combinação de cultura, comunicação e consenso é uma maior eficiência das decisões e um comportamento decisório mais racional (CHOO, 2003, p. 247248).

No processo de tomada de decisão, é fundamental ter disponíveis dados, informações e conhecimentos, mas esses geralmente estão dispersos, fragmentados e armazenados na cabeça dos indivíduos e experimentam influência de seus modelos mentais. A tomada de decisão precisa ser fruto de um processo estruturado, que abarca o estudo do problema a partir de um levantamento de dados, produção de informação, estabelecimento de propostas de soluções, escolha da decisão, viabilização e implementação da decisão e análise dos resultados obtidos.

No que tange a tomada de decisões nas organizações é importante salientar que esta requer informações que sejam capazes de reduzir a incerteza de pelo menos três formas: a informação é fundamental para estruturar uma situação de escolha; a informação é imprescindível para definir preferências e selecionar regras; são fundamentais no que se refere a alternativas viáveis e suas possíveis consequências. 0 que se pode afirmar é que "grande parte da busca de informação visa identificar, desenvolver e avaliar diversos cursos de ação" (CHOO, 2003, p. 295). Isto posto é fundamental conhecer as premissas da informação para a tomada de decisão frente às necessidades cognitivas, reações emocionais e dimensões situacionais. 
Cabe destacar que a tomada de decisões na organização demanda informações capazes de minimizar a incerteza de no mínimo três maneiras: a informação é necessária para compor uma situação de escolha; a informação é necessária para determinar preferências e eleger regras e, são necessárias informações sobre alternativas viáveis e suas possíveis implicações. Além do mais, durante o processo de tomada de decisões, a busca de informação é guiada pelos hábitos e princípios que o indivíduo conquistou em consequência de treinamento, educação ou experiência. Ao mesmo tempo, as organizações criam e legitimam regras e rotinas para compor os comportamentos de busca e de escolha com base nos objetivos organizacionais. Por conseguinte, a busca da informação é produto das preferências individuais, dos valores institucionais e dos atributos da situação de escolha (CHOO, 2003).

\section{PROCEDIMENTOS METODOLÓGICOS}

As pesquisas podem ser classificadas quanto à abordagem, quanto aos fins e quanto aos meios. Quanto à abordagem, este estudo se caracteriza como uma pesquisa qualitativa. Para Minayo (2001), a pesquisa qualitativa trabalha com o universo de significados, motivos, aspirações, crenças, valores e atitudes, o que corresponde a um espaço mais profundo das relações, dos processos e dos fenômenos que não podem ser reduzidos à operacionalização de variáveis.

Quanto aos fins, a pesquisa desenvolvida neste trabalho é descritiva, o que significa que ela busca identificar as características de uma determinada população e as relações entre diferentes variáveis (GIL, 2010). No caso, o estudo se detém na descrição do comportamento informacional de líderes de igrejas cristãs e, como tal, busca descrever o comportamento destes sujeitos.

Quanto aos meios, a pesquisa constitui um estudo de caso que, segundo Godoy (1995) diz respeito a um tipo de pesquisa que objetiva realizar uma análise profunda do tema e do objeto de estudo, visando o exame detalhado do ambiente, sujeito ou situação específica.

Na presente pesquisa, os casos estudados se referem a duas modalidades de igrejas cristãs, as quais, devido à sua forma de organização, definem tarefas diferentes para as pessoas que as administram e que, exercem papeis de líderes religiosos. 
Portanto, trata-se de um estudo de caso exploratório descritivo, havendo duas unidades de análise e diferentes sujeitos de pesquisa, os quais representam as referidas unidades.

A unidade de análise objeto deste trabalho são igrejas cristãs, portanto representantes de uma postura religiosa única - o Cristianismo, mas que ao longo dos anos ganharam diferenças significativas, as quais passaram a determinar ações diferenciadas dos líderes e administradores ligados a cada uma delas.

No caso desta pesquisa, a unidade definida como Igreja Católica é representada por seis padres, cujo trabalho se desenvolve na capital de Minas Gerais, Belo Horizonte. A outra unidade de pesquisa, representada pelas Igrejas Evangélicas, é representada por seis pastores dessas igrejas evangélicas que atuam em Belo Horizonte. Trata-se, portanto, de uma amostra não-probabilística, intencional, por acessibilidade. 0 acesso a esses sujeitos de pesquisa foi feito mediante um contato individual via telefone aos sujeitos envolvidos.

A palavra Igreja, adotada nesta pesquisa, faz alusão à congregação dos fiéis cristãos, ao conjunto do clero e ao povo de um determinado território onde o cristianismo possui adeptos. No caso da Igreja Católica, a administração tem diferentes níveis, havendo arcebispados, dioceses e outras subdivisões, cada uma delas responsável por um conjunto de paróquias, sendo cada paróquia entregue à administração de um vigário (FALCÃO, 2004). Já no caso da Igreja Evangélica existem diferentes orientações religiosas e cada uma delas tem uma liderança central que orienta um conjunto de igrejas que partilham esta orientação. Embora todos os cristãos aceitem as palavras da Bíblia, seus seguidores ligados às duas principais orientações as interpretam de maneiras diferentes e no caso das igrejas evangélicas se formam grupos distintos que possuem diferenças entre si (NOLL, 2011).

Para a coleta de dados foi utilizado um roteiro de entrevista, constituído de questões que permitem identificar o exercício da gestão pelo entrevistado e, sobretudo seu comportamento informacional. Nesta pesquisa foram realizadas entrevistas com 12 participantes, destes, 6 são padres e 6 são pastores. Essas entrevistas objetivaram analisar como ocorre o processo de busca e uso da informação por líderes religiosos para embasar o processo de tomada de decisão em seu dia a dia. Por fim, os dados coletados foram analisados por meio da análise de conteúdo em que foram feitas as inferências pela pesquisadora. 


\section{ANÁLISE E INTERPRETAÇÃO DOS RESULTADOS}

As informações que seguem foram fruto de entrevistas realizadas entre os meses de junho a setembro de 2018, objetivando analisar como ocorre o processo de busca e uso da informação por líderes religiosos para embasar o processo de tomada de decisão em seu dia a dia. Foram entrevistados 12 líderes religiosos, sendo 6 padres e 6 pastores.

Dos 12 entrevistados apenas 1 é do gênero feminino e a faixa etária dos entrevistados situa-se entre 37 e 69 anos. Destaca-se ainda que somente a respondente do gênero feminino não possui curso superior e dos 12 participantes 6 possuem outra atuação profissional além da liderança religiosa. Outro dado importante diz respeito ao número de fiéis das Igrejas, notamos um número elevado de fiéis nas Igrejas citadas, média de 14.000 fiéis mensalmente, tal fato pode estar associado à importância da religião na vida das pessoas tendo em vista que esta é responsável por conduzir seus fiéis a determinados valores, rituais, princípios e ensinamentos que dão sentido à vida das pessoas.

Iniciando as perguntas buscamos compreender qual é a atribuição dos padres e dos pastores. Com base nos dados coletados é possível destacar alguns componentes fundamentais para se pensar em relação ao papel do líder religioso. Primeiro, sua importância em relação ao conjunto de crenças e práticas desenvolvidas por este que são capazes de aglutinar um número de indivíduos, criando, a partir de então, práticas e crenças comuns entre as pessoas que os seguem. Segundo a importância deste líder na condução e administração dos bens da Igreja e de toda a estrutura vinculada a ela, entretanto, é importante destacar que em se tratando dos templos cristãos, os líderes religiosos não são os únicos na tomada de decisões, estes fazem parte de uma estrutura mais ampla responsável pela gestão da Igreja.

Outro ponto importante a ressaltar diz respeito à existência de uma estrutura hierárquica em todas as igrejas participantes, seguida de uma estrutura técnicoadministrativa que condiz com a quantidade de fiéis que recebe mensalmente. Assim, com base em tal fato podemos identificar em tais igrejas um ambiente organizacional que, diferente das organizações comuns, promove a experiência de transcendência. Embora, a rigor, as Igrejas sejam reconhecidas por seus aspectos sagrados, "a religião pode ser considerada como uma mercadoria, estabelecendo uma estrutura 
transnacional para viabilizar da melhor forma possível a exposição e a expansão de seu produto" (FONSECA, 2014, p. 49).

Dando sequência à pesquisa destacamos as necessidades informacionais dos líderes religiosos pesquisados. Notamos que as necessidades informacionais destes estão pautadas principalmente por questões religiosas que visam auxiliar o exercício do sacerdócio e em seguida por conhecimentos gerais com o intuito de auxiliar sobre as questões da atualidade. Alguns citam em menor proporção questões institucionais e de gestão.

De acordo com Choo (2003), as necessidades de informação frequentemente são entendidas como as necessidades cognitivas de determinada pessoa, isto é, aquelas relacionadas às falhas ou deficiências de conhecimento. Ou seja, a necessidade de informação origina-se do momento em que o indivíduo identifica lacunas em seu conhecimento e em sua habilidade de dar significado a uma experiência. Pautado nisso, a busca da informação é a maneira na qual o indivíduo dedica-se em busca de informações a fim de mudar seu estado de conhecimento.

Com base nos conceitos de necessidade, busca e uso da informação, perguntamos aos líderes religiosos que tipo de fontes (documentais e eletrônicas) eles usam para se informar diariamente. A partir das respostas destacamos: jornais impressos e eletrônicos, e-mails, WhatsApp, rádios, sites diversos, televisão, informativos institucionais, boletins internos da instituição, arquivos da Igreja, a Bíblia, periódicos seculares, redes sociais e o contato com a comunidade.

Em relação ao acesso às fontes de informação em termos de tempo e de custo os líderes religiosos mencionam que o tempo despendido gira em torno da necessidade do momento. Já em relação ao custo mencionam ter gastos com o pacote de internet, com a compra de jornais e revistas impressos e com a manutenção esporádica dos equipamentos.

No que concerne à disseminação de informação por parte dos líderes religiosos notamos que há uma preocupação com a divulgação de informações de cunho religioso ligadas às celebrações e aos sacramentos. Há também a divulgação de eventos, pastorais, campanhas, obras de recuperação, ou seja, informações voltadas para a vida cotidiana da Igreja que sejam úteis aos fiéis. Além de informações religiosas, há a preocupação na divulgação de questões políticas, sociais, educacionais ou atualidades diversas, todas pautadas na evangelização da comunidade. 
Sobre o objetivo da divulgação das informações percebemos que se fundamenta na necessidade de orientação espiritual e orientações diversas, estas visam o conhecimento e aprendizado dos fiéis, no sentido de fortalecer, encorajar e engajar os fiéis na participação ativa das atividades da Igreja. Para Choo (2003, p. 405), “o objetivo da distribuição da informação é promover e facilitar a partilha de informações, que é fundamental para a criação de significados, a construção de conhecimento e a tomada de decisões".

Em relação à qualidade e à confiabilidade das informações divulgadas pelos líderes religiosos eles afirmam que há qualidade nas informações tendo em vista que buscam ser precisos, pontuais, direcionados e específicos garantindo assim $100 \%$ de confiabilidade, pois as informações divulgadas são pautadas na veracidade e na imparcialidade, além do mais buscam difundir apenas aquilo que será útil ao público.

Em se tratando da qualidade e da confiabilidade das informações é importante compreender o valor da informação, assim, perguntamos aos líderes religiosos se as informações divulgadas podem ser consideradas relevantes. Notamos, de acordo com a percepção dos líderes religiosos, que as informações divulgadas por eles são relevantes, tendo em vista que estas ajudam os fiéis na reflexão de questões que permeiam sua vida. Aqui, podemos afirmar que o valor de uso de uma informação ou sua relevância baseiase na utilização final que se fará dela. Por ser um bem abstrato e intangível, o seu valor estará associado a um contexto. 0 ponto importante é que a informação precisa atender às necessidades de uma pessoa ou de um grupo, podendo ser usada como um insumo para a tomada de decisão, se for necessário.

Há que se destacar que qualquer que seja o método de decisão é fundamental ter em mente a estrutura e a clareza dos objetivos organizacionais. Baseado nisso, perguntamos aos líderes religiosos quais decisões estão atreladas a eles em sua Igreja. Os entrevistados deixam clara a existência de uma estrutura hierárquica dentro de suas respectivas Igrejas, limitando suas decisões. Segundo os respondentes é necessário atender as diretrizes da organização por meio de regras formais o que leva a um comportamento regulado por normas e rotinas, de forma que a organização possa atuar de uma maneira procedimental e intencional em relação às decisões a serem tomadas.

Dando prosseguimento à coleta de dados buscamos compreender quais são os meios de comunicação e de obtenção de informação utilizados pelos líderes religiosos para a tomada de decisões relacionadas à sua instituição. É possível perceber que as 
decisões são baseadas em diversos fatores: nas diretrizes institucionais, em documentos internos, nos princípios bíblicos, em reuniões, no bem-estar dos envolvidos e na experiência de cada um. É possível afirmar que "a busca da informação é fruto das preferências individuais, dos valores institucionais e dos atributos da situação de escolha" (CHOO, 2003, p. 303).

O uso da informação é a seleção e o processamento das informações, que resultam em novos conhecimentos ou ações. A informação é usada para responder a uma questão, solucionar um problema, tomar uma decisão, negociar uma posição ou dar sentido a uma situação (CHOO, 2003, p. 115-116).

Choo (2003) afirma que a busca e o uso da informação se caracterizam por um processo dinâmico e socialmente desordenado que se divide em níveis de contingências cognitivas, emocionais e situacionais. A informação reproduzida responde a aspectos sobre os atributos das pessoas, objetos e fatos, sobre a forma como eles se relacionam, e sobre as implicações e razões de ações ou acontecimentos.

Ainda sobre os meios de comunicação e de obtenção de informação utilizados pelos líderes religiosos perguntamos se as informações acessadas e utilizadas diariamente contribuem para a tomada de decisão junto à instituição em que atuam. Os líderes afirmam que as informações acessadas por eles contribuem sim para a tomada de decisão, uma vez que geram a compreensão maior sobre determinado problema, esclarecem dúvidas, servem de atualização, orientam e dão segurança na realização de seu trabalho, afirmam ainda que mesmo em situações rotineiras permitem a correção de percursos, além de possibilitarem novas decisões.

A tomada de decisão é uma prática constante dentro das organizações. Todavia, por vezes, ela está imersa em um ambiente de vasta complexidade, em que a necessidade de informação advém de problemas, incertezas e ambiguidades ligadas a experiências e situações específicas de uma organização e que exigem a compreensão de como tecnologias, cultura, valores e habilidades podem auxiliar para transformá-las em oportunidades. São experiências e fatores que se relacionam a aspectos contextuais, sociais e pessoais que frequentemente criam dificuldades para a tomada de decisão, mas que precisam ser transformados em ação para que se atinja um desempenho adequado.

Para satisfazer as necessidades de informação, é necessário retomar as informações que respondam aos questionamentos elaborados. 0 planejamento e a tomada de decisão correspondem aos principais geradores de necessidades cognitivas de informação. Nesse sentido, torna-se necessário que a informação satisfaça tanto às 
necessidades cognitivas, quanto às afetivas e situacionais. Tendo atendido tais necessidades, torna-se possível, por meio do planejamento, determinar de forma clara os objetivos organizacionais e se tomar decisões sobre as alternativas mais viáveis para se alcançar tais objetivos (CHOO, 2003, CHOO; JOHNSTON, 2004).

\section{CONCLUSÃO}

A informação é um dos elementos mais importantes no cotidiano do ser humano. Um líder que perceba tal importância terá em suas mãos a possibilidade de gerar conhecimento e aperfeiçoar o curso das informações dentro da organização, sendo assim, esta pesquisa visou analisar como ocorre o processo de busca e uso da informação por líderes religiosos para embasar o processo de tomada de decisão em seu dia a dia.

A criação de significado vincula-se com a assimilação das mensagens sobre o ambiente. Primeiro é necessário identificar o que ocorre neste ambiente, em seguida é preciso dar sentido a estes acontecimentos para posteriormente interpretá-los, visando direcionar a ação para uma decisão.

A construção do conhecimento representa o cerne do processo de uso da informação dentro de uma organização. Ela é motivada por uma situação que evidencia lacunas no conhecimento atual. A construção do conhecimento é alcançada quando há sinergia entre o conhecimento tácito e o conhecimento explícito gerando assim novos conhecimentos.

Já a tomada de decisão ocorre de forma natural após a criação de significados e da construção de conhecimento. Ela é provocada pela necessidade de escolher o curso de uma ação.

Sendo assim, foi possível perceber que as organizações religiosas necessitam de legitimação para seu funcionamento. Disso resulta a importância da liderança religiosa como figura central, pois o líder, além de legítimo, precisa ter domínio sobre o grupo que lidera. Este líder produz a coesão interna do grupo tanto na esfera das representações como também nas práticas religiosas. Este possui grande importância no que diz respeito ao conjunto de crenças e práticas desenvolvidas que são capazes de agregar um número de indivíduos, criando práticas e crenças comuns entre as pessoas que os seguem. Além do mais, este líder é fundamental na condução e gestão dos bens da Igreja 
e de toda a estrutura vinculada a ela, entretanto, como demonstrado nesta pesquisa, os padres e pastores não são os únicos na tomada de decisões, estes fazem parte de uma estrutura mais ampla responsável pela gestão da Igreja.

No que diz respeito à necessidade informacional, esta é motivada pela necessidade de se corresponder a uma lacuna de conhecimento em uma dada situação que demanda uma escolha ou decisão por parte de um indivíduo. Podemos perceber que as necessidades informacionais dos líderes religiosos investigados estão pautadas, sobretudo por questões religiosas que visam auxiliar o exercício do sacerdócio, entretanto, há uma necessidade de acesso a conhecimentos gerais que visam auxiliar estes líderes em questões sobre a atualidade. Há ainda em menor proporção a necessidade por questões institucionais e de gestão.

Em relação à busca de informação, esta surge para satisfazer uma dada necessidade de conhecimento com o intuito de minimizar um estado de incerteza ou ambiguidade que permeia uma situação em que uma decisão é necessária. Já o uso da informação ocorre quando uma pessoa elege e processa informações visando uma mudança no estado de conhecimento ou em sua capacidade de agir.

Já a divulgação da informação diz respeito à forma como a informação é disseminada pela organização e tem o objetivo de promover e facilitar o compartilhamento de informações que facilitam a criação, a construção de conhecimento e a tomada de decisões. A distribuição da informação é o método pelo qual as informações se disseminam pela organização de forma que a informação adequada alcance a pessoa certa no momento, lugar e forma adequados.

Com base nisso, é possível perceber que os líderes religiosos estão preocupados com o sentido da informação, as condições, padrões e regras de uso. Aqui a organização, por meio dos líderes, cria suas regras e estruturas com foco em suas intenções estratégicas. Ou seja, a geração e transformação da informação são adaptadas com base na cultura organizacional, seus propósitos, suas regras, rotinas e papeis, ou seja, nesta pesquisa percebemos que os líderes se preocupam em se ater a informações de cunho religioso com o objetivo de difundir a fé, tendo em vista que estas informações são direcionadas aos fiéis, além de informações religiosas, há a preocupação na divulgação de questões políticas, sociais, educacionais ou atualidades diversas, todas pautadas na evangelização da comunidade. 
A partir dos relatos dos líderes religiosos percebemos que o objetivo de se divulgar determinada informação aos fiéis se baseiam na necessidade de orientação espiritual e orientações diversas, estas visam o conhecimento e aprendizado, no sentido de fortalecer, encorajar e engajar os fiéis na participação ativa das atividades da Igreja.

No que tange à tomada de decisões esta está voltada para objetivos e orientada por problemas, e o comportamento de escolha é regido por normas e rotinas, de forma que a organização seja capaz de agir de forma procedimental e intencionalmente racional. Percebemos que os entrevistados deixam clara a existência de uma estrutura hierárquica em suas respectivas Igrejas, o que limita suas decisões dentro de sua instituição. Uma questão fundamental para as organizações é definir as premissas que orientam a tomada de decisões. A organização deve idealizar esse ambiente do qual o indivíduo se aproximará cada vez mais da racionalidade e dos objetivos da organização em suas decisões.

É possível verificar que as decisões são baseadas nas diretrizes institucionais, em documentos internos, nos princípios bíblicos, em reuniões, no bem-estar dos envolvidos e na experiência de cada um. Destacamos aqui que a busca e o uso da informação são processos dinâmicos e se dividem em níveis de contingências cognitivas, emocionais e situacionais. A informação reproduzida pelos líderes responde a aspectos sobre os atributos das pessoas, objetos e fatos, sobre a forma como eles se relacionam, e sobre as implicações e razões de ações ou acontecimentos.

Com base na análise observamos que as informações acessadas e utilizadas pelos líderes religiosos possibilitam a compreensão de determinado problema, esclarecem dúvidas, servem de atualização, orientam e dão segurança na realização de seu trabalho, e, mesmo em situações rotineiras permitem a correção de percursos, além de possibilitarem novas decisões.

Cabe destacar que a prática da tomada de decisão está imersa em um ambiente de extensa complexidade, em que a necessidade de informação decorre de problemas, incertezas e ambiguidades vinculadas a experiências e situações próprias de uma organização e que exigem a percepção de como os diversos fatores envolvidos podem colaborar para transformá-las em oportunidades. São experiências e fatores que se relacionam a aspectos sociais, contextuais e pessoais que precisam ser transformados em ação para que se alcance um desempenho adequado e, segundo os líderes 
entrevistados, há o cumprimento dos objetivos estabelecidos, alcançando os resultados desejados.

Assim, a partir da análise realizada no que concerne ao alcance dos objetivos é possível afirmar que estes foram cumpridos, uma vez que a discussão contemplou cada ponto delimitado.

\section{REFERÊNCIAS}

BARBOSA, Ricardo Rodrigues. Acesso e necessidades de informação de profissionais brasileiros: um estudo exploratório. Perspectivas em Ciência da Informação, Belo Horizonte, v. 2, n. 1, p. 5-35, 1997.

BARBOSA, Ricardo Rodrigues. Gestão da informação e do conhecimento: origens, polêmicas e perspectivas. Informação \& Informação, Londrina, v. 13, n. esp., p. 125, 2008.

BERGER, P. L. 0 Dossel Sagrado. Elementos para uma teoria sociológica da religião. São Paulo: Paulus, 1985.

CARDOSO, Ana Maria Pereira. Pósmodernidade e informação: conceitos complementares. Perspectivas em Ciência da Informação, Belo Horizonte, v. 1. n. 1, p. 63-79, jan./jun. 1996.

CHOO, C. W. A organização do conhecimento: como as organizações usam a informação para criar significado, construir conhecimento e tomar decisões. Tradução: Eliana Rocha. São Paulo: Senac, 2003.

\section{CHOO, C. W. Information Management} for the Intelligent Organization: the art of scanning the environment. 3rd ed. Medford: Information Today, 2002.

CHOO, C. W.; JOHNSTON, R. Innovation in the knowing organization: a case study of an e-commerce initiative. Journal of
Knowledge Management, v. 8, n. 6, p. 77-92, 2004.

FALCÃO, Manuel Franco. Enciclopédia Católica Popular. Belo Horizonte: Paulinas, 2004.

FONSECA, A. Brasil. Fé na tela: características e ênfases de duas estratégias evangélicas na televisão. Revista Religião e Sociedade, Rio de Janeiro, v. 23, n. 2, p. 33-52, 2014.

GIL, Antônio Carlos. Como elaborar projetos de pesquisa. 5. ed. São Paulo: Atlas, 2010.

GINMAN, M. Cultura Informação e desempenho empresarial. IATUL Quarterly. A Journal of Management and Technology, v. 2, n. 2, p. 93-106, 1988.

GODOY, Arilda Schmidt. Introdução à pesquisa qualitativa e suas possibilidades. RAE - Revista de Administração de Empresas, São Paulo, v. 35, n. 2, p. 57-63, 1995.

LE COADIC, Yves-François. A ciência da informação. Tradução: Maria Yêda F. S.de Filgueiras Gomes. 2. ed. Brasília: Briquet de Lemos/Livros, 2004.

LOPES, E. C.; VALENTIM, M. L. P. Mediação da informação no âmbito do mercado de capitais. Informação \& 
Informação, Londrina, v. 13, n. esp., p. 87-106, 2008.

MARTELETO, Regina Maria. Cultura informacional: construindo o objeto informação pelo emprego dos conceitos de imaginário, instituição e campo social. Ciência da Informação, Brasília, v. 24, n. 1, p. 89-93, jan./abr. 1995.

MINAYO, Maria Cecília de Souza (org.). Pesquisa Social: teoria, método e criatividade. 18. ed. Petrópolis: Vozes, 2001.

MORESI, Eduardo Amadeu Dutra. 0 contexto organizacional. In: TARAPANOFF, Kira. (org.). Inteligência Organizacional e Competitiva. Brasília: Editora UnB, 2001. p. 59-91.

NOLL, Mark A. Protestantism: a very short introduction. Oxford: Oup Oxford, 2011.

NONAKA, I.; TAKEUCHI, H. Criação de conhecimento na empresa: como as empresas japonesas geram a dinâmica da inovação. 4. ed. Rio de Janeiro: Campus, 1997.

NONAKA, I.; TAKEUCHI, H. Gestão do conhecimento. Porto Alegre: Bookman, 2008.

OTTONICAR, Selma Leticia Capinzaiki; NASCIMENTO, Natália Marinho do; BASSETTO, Clemílton Luís. 0 comportamento informacional e a competência em informação: uma abordagem para geração de inovação em micro e pequenas empresas. Encontros Bibli: Revista Eletrônica de Biblioteconomia e Ciência da Informação, v. 23, n. 52, p. 18- 33, maio/ago. 2018.
PACHECO, Leila Maria Serafim. A informação enquanto artefato. Informare, Rio de Janeiro, v. 1, n. 1, p. 20-24, jan./jun. 1995.

SILVA, R. R. 0 trabalho de líderes religiosos em organizações protestantes neopentecostais e tradicionais. In: EM A. M. Mendes (org.). Psicodinâmica do trabalho. Teoria, método e pesquisas. São Paulo: Casa do Psicólogo. 2007, p. 283-302.

SILVEIRA, Martha Martínez; ODDONE, Nanci.Necessidades e comportamento informacional: conceituação e modelos. Ciência da Informação, Brasília, v. 36, n. 2, p. 118-127, maio/ago. 2007.

SIMON, H. Comportamento

Administrativo: estudo dos processos decisórios nas organizações administrativas. Tradução: Aluízio Loureiro Pinto. Rio de Janeiro: Editora da FGV, 1979.

TARAPANOFF, Kira (org.). Inteligência Organizacional e Competitiva. Brasília: Editora UnB, 2001.

WILSON, T. D. Human information behavior. Informing Science Research, Colorado, v. 3, n. 2, 2000.

WILSON T. D. Models in Information Behaviour Research. Journal of Documentation, v. 55, n. 3, p. 249-270, 1999.

VITELL, S. J.; PAOLILLO, J. G. P.; SINGH, J. J. Religiosity and Consumer Ethics.

Journal of Business Ethics, Springer, v. 57 , p. 175-181, 2005. 